\title{
JORNADAS DE TRABALHO SOBRE O MODELO DE FORMAÇÃO INICIAL DE PROFESSORES DO ENSINO SECUNDÁRIO DA UNIVERSIDADE DE SEVILHA
}

SÉRGIO CLAUDINO ${ }^{1}$

De 27 a 29 de Janeiro de 1997, realizaram-se no Instituto de Ciências da Educação/ICE da Universidade de Sevilha as Jornadas de trabajo sobre el modelo de formación inicial de profesores y profesoras de educación secundaria, com a participação de docentes que neste Instituto e no Departamento de Geografia da Faculdade de Letras da Universidade de Lisboa trabalham na formação inicial de docentes. No âmbito das Jornadas, visitámos escolas com centros de formação de professores de Geografia e História, coordenados pelo ICE e, ainda, o Centro de Formação de Professores/CEP de Sevilha, cuja actividade está direccionada para a formação contínua.

Por ser quase desconhecido entre nós, faremos aqui uma breve referência ao modelo de formação inicial do ICE da Universidade de Sevilha, bem como às alterações em discussão e, ainda, ao balanço da formação contínua desenvolvida pelo CEP.

Em 1970, a Lei Geral de Educação atribui aos Institutos de Ciências da Educação/ICEs das Universidades a formação inicial de professores do ensino secundário, através de um curso que permite a obtenção do Certificado de Aptitud Pedagógica/CAP, designação por que acaba de ser conhecido o próprio curso. Em 1985, na sequência do processo de regionalização, as autoridades educativas da Andaluzia determinam que o CAP seja orientado para a formação dos professores do ensino secundário. Com a presente reforma educativa, este grau de ensino compreende seis níveis escolares e é frequentado por jovens dos 12 aos 18 anos.

O ICE da Universidade de Sevilha, onde o curso de formação inicial é leccionado desde 1972-73, não dispõe de corpo docente próprio, sendo este recrutado principalmente entre professores do ensino secundário. O Instituto é financiado na sua maior parte pelos alunos que nele se inscrevem.

1 Assistente da Faculdade de Letras, Universidade de Lisboa. Investigador do Centro de Estudos Geográficos da Universidade de Lisboa. Centro de Estudos Geográficos, Faculdade de Letras, Cidade Universitária, 1699 LISBOA Codex. Tel: (351-1) 7965162; Fax: (351-1) 7960063; sclaudino@mail.telepc.pt. 
Actualmente, o CAP da Universidade de Sevilha tem a duração de um semestre e divide-se em duas fases. A primeira, com a duração de 60 horas, é mais teórica, decorre entre meados de Novembro e Dezembro e compreende os módulos de Teoria da Educação (10 horas), Psicologia da Educação (20 horas), Didáctica Geral (30 horas) e a primeira fase das Práticas, as Práticas de Imersão (15 horas), uma das principais inovações do curso. Nelas, os alunos, orientados por um inquérito fornecido no Instituto, visitam uma escola, identificam o seu funcionamento, dialogam com professores e alunos, familiarizando-se e reflectindo sobre a realidade escolar, agora do ponto de vista de futuros professores. Esta abordagem aposta intencionalmente na escola como centro educativo, em oposição a uma visão redutora da mesma como local onde se sucedem as aulas. Os resultados da observação são debatidos em módulos que os alunos frequentam no ICE e, em grupos mais pequenos, com um professor tutor da escola visitada.

A segunda fase do curso decorre entre Janeiro e Março. É então leccionado o módulo de Didáctica Especial (30 horas), que integra, ainda, as Práticas de Ensino ou de Intervenção (com um mínimo de também 30 horas).

A Didáctica Especial das Ciências Sociais, Geografia e História está aberta à frequência de licenciados pela Universidade de Sevilha naquelas áreas, predominando os diplomados em cursos de História. Um dos objectivos deste módulo de Didáctica ajuda-nos também a reconhecer as finalidades do curso:

Adquirir uma atitude básica em relação à profissão de "ensinante" que, sem deixar de ser realista, seja também construtiva, crítica e não desvinculada da dimensão "social" (e não meramente "técnica") do ensino, fundamentando sobre a mesma atitude um modelo de desenvolvimento profissional desejável. ${ }^{2}$

O ICE de Sevilha valoriza a identificação das imagens e das expectativas prévias de formação dos alunos, que orienta numa perspectiva construtivista. O programa de Didáctica Especial das Ciências Sociais, Geografia e História revela (uma vez mais...) a preocupação em justificar a existência daquela área disciplinar no ensino secundário e pretende partir da definição do seu papel formativo para a construção de um modelo de trabalho didáctico coerente com os enunciados teóricos.

As Práticas de Intervenção, coordenadas pelo docente de Didáctica Especial, são orientadas directamente nas escolas pelo já referido professor tutor.

Este é seleccionado num concurso público, depois de apreciado o plano de trabalho que elabora, em consonância com os objectivos do módulo de Didáctica Especial. Não tem qualquer redução do seu horário lectivo, recebe do ICE um reduzido subsídio anual pela sua colaboração e, tal como em Portugal, o exercício destas funções não tem relevância para a progressão na carreira docente. Sujeitos a

2 Garcia Pérez, F. F. (s.d.) - Curso para la Obtención del C.A.P. 1996-97 - Didáctica de las Ciencias Sociales, Geografia e Historia. Instituto de Ciencias de la Educacion, Universidad de Sevilla. p. 3 (pol.) 
um concurso de selecção e com condições de trabalho piores que as oferecidas no nosso país aos orientadores de estágio, teremos de procurar no voluntarismo a principal justificação para a disponibilidade revelada por estes formadores.

Os formandos elaboram e fundamentam a planificação de uma unidade ou de uma sequência didáctica, com o apoio do professor de Didáctica Especial e do tutor. Implementam depois, como professores, a sua planificação numa das turmas deste que, tal como os seus colegas, assiste às aulas e as discute - após o enfoque das Práticas de Imersão na escola, como contexto educativo, privilegia-se, agora, o trabalho na sala de aula.

Nesta fase, a classificação dos alunos depende fundamentalmente da apreciação do professor tutor e é ratificada pelo docente do Instituto.

Em 1996/97, no âmbito do CAP da Universidade de Sevilha, abriram cinco grupos de Didáctica Especial de Geografia e História, num total de 35 alunos. No início do ano lectivo tinham-se inscrito 160 alunos nesta especialidade, pelo que a grande maioria destes desistiu ou não obteve aproveitamento na primeira fase do curso.

O carácter intensivo da formação ministrada, o elevado número de alunos por turma e o facto de, como referiremos adiante, poucos deles terem reais oportunidades de virem a exercer a actividade docente, sugerem-nos uma formação inicial mais superficial que a definida nos objectivos do curso e ajudam-nos a compreender a discrepância entre o número de inscritos e de diplomados.

Concluído o CAP, aqueles que desejarem exercer a actividade docente candidatam-se a um exame de âmbito nacional (a oposicion, que não se realiza todos os anos), onde são avaliados sobre os seus conhecimentos científicos e pedagógicos.

$\mathrm{O}$ recrutamento de professores depende unicamente deste exame e ignora completamente a classificação obtida na formação inicial; os novos docentes são avaliados no seu primeiro ano de docência, mas a sua classificação é invariavelmente positiva. Este modelo de selecção enquadra-se nos princípios de recrutamento do funcionalismo público espanhol mas poderá, igualmente, denunciar a falta de confiança dos responsáveis públicos na formação acreditada pelos ICEs. De recordar que à diversidade de legislação entre as Comunidades Autónomas acresce a liberdade de organização do CAP pelas universidades, o que tem permitido o funcionamento, na prática, de cursos com a duração total de apenas uma semana, a inscrição alunos não licenciados no CAP, etc. A aparente liberalidade de funcionamento do CAP tem contribuído, de resto, para algumas situações de legalidade duvidosa, e divulgadas publicamente.

Nos últimos anos, no ICE de Sevilha o número de estudantes tem aumentado anualmente em cerca de 400 (1800 em 1996/97), apesar de diminuírem as vagas para docentes no sistema público de ensino - actualmente, apenas cerca de $2 \%$ dos que concluem o curso conseguem exercer a actividade docente.

Segundo os responsáveis do ICE, alguns dos seus alunos gostariam de ser professores mas não o conseguem, outros admitem essa hipótese no seu futuro profissional e, por fim, vários outros recusam liminarmente vir a exercer a actividade docente. 
A que se deverá o aparente paradoxo da frequência crescente de um curso que dá cada vez menores garantias de emprego?

As dificuldades dos licenciados em ingressarem no mercado de trabalho levarão os mesmos a procurar enriquecer a sua formação com o máximo de cursos; o CAP significará, para muitos dos que nele se diplomam, tão somente um curso de 180 horas que constará do seu currículo e poderá ajudar à obtenção de um emprego.

As observações que efectuámos em quatro escolas onde funcionam Centros de Educação Secundária, vão, de alguma forma, ao encontro das nossas expectativas: formandos com diferentes tipos de motivação para a actividade docente e uma prática lectiva centrada nestes professores que, em Janeiro, se esforçam sobretudo por desenvolver a sua capacidade de comunicar com os alunos.

O modelo de formação inicial do CAP encontra-se prestes a ser substituído pelo curso de Qualificação Pedagógica, instituído pelo Decreto Real 1692/1995, de 20 de Outubro, mas que ainda aguarda a sua regulamentação em cada Comunidade Autónoma e o acordo entre o respectivo governo e cada uma das suas universidades.

A carga lectiva é substancialmente aumentada para 600 a 750 horas de formação, durando o curso um mínimo de um ano lectivo. Mantém-se a divisão num bloco teórico-prático geral e num outro de prática profissional docente, permanecendo a preocupação em integrar a formação teórica e prática, numa perspectiva de reflexão e acção.

A formação geral comum a todos os diplomados compreende Sociologia da Educação. Teoria e Instituições Contemporâneas (4 créditos, de 10 horas cada); Psicologia Evolutiva e da Educação (5 créditos); Desenho e Desenvolvimento do Currículo Escolar (5 créditos); Atenção à Diversidade. Tutoria e Orientação Educativa (5 créditos); e, por fim, Matérias Obrigatórias Específicas (13 créditos). Nas matérias optativas (a que correspondem 9 créditos), procura-se contemplar lacunas da formação universitária, designadamente Novas Tecnologias no Ensino Secundário, Educação Ambiental e Ciência, Técnica e Sociedade.

O Ensino da Prática Profissional Docente (25 créditos) compreende a planificação, execução e avaliação da prática lectiva, num total de 70 unidades de crédito.

A Propuesta de Organización y Plan de Estudios para el Curso de Cualificacion Pedagógica, assinada por Luis Martín Muncharaz e José Martín Toscano, do ICE da Universidade de Sevilha, assume-se como uma tomada de posição perante a iminente publicação pela Administração Educativa de Andaluzia da regulamentação da reforma.

Esta proposta defende uma alteração radical no recrutamento dos futuros professores formandos. Antes de ingressarem no curso de formação profissional, os candidatos a docentes serão sujeitos a exames públicos nacionais, que só incidirão em conteúdos científicos. Apenas os apurados neste exame, que sabem ir exercer a actividade docente, frequentarão o curso de Qualificação Pedagógica.

A proposta de alteração aguardava, aquando da nossa visita, a reacção dos responsáveis educativos, mas não tivera, desde logo, grande aceitação.

$\mathrm{Na}$ visita ao Centro de Formação de Professores de Sevilha fomos recebidos 
pela assessora de Didáctica das Ciências Sociais e directora do mesmo Centro.

Instalado num antigo convento do centro da cidade, dispõe de verbas relativamente avultadas, que lhe permitem ter um apetrechado Centro de Documentação, promover a publicação de diversos trabalhos sobre a actividade lectiva $\mathrm{e}$ suportar financeiramente diversas modalidades de formação contínua. O CEP tenta descentralizar as actividades de formação contínua, apoiando os grupos de professores que apresentam projectos de formação ou que solicitam localmente cursos de formação. Existe uma grande tensão com a Universidade de Sevilha (não com o seu ICE, com o qual o CEP colabora), que pretenderá assegurar a formação contínua de professores. A tensão vivida no CEP prende-se ainda com o receio de que as novas orientações políticas sejam hostis à sua actividade, como algumas medidas anunciadas parecem confirmar.

As autoridades educativas valorizam principalmente o papel do CEP na formação contínua de um corpo docente confrontado com uma reforma educativa em implementação. No Centro de Sevilha considera-se que a mesma deve ajudar a suprir as lacunas da débil formação inicial, pretendendo-se o desenvolvimento de uma prática de investigação-acção a partir de um tema-problema, fugindo a uma formação vertical.

A responsável do Centro diferenciou os docentes que solicitam apoio para a sua formação contínua, desenvolvida em grupos de trabalho de reflexão ou através de acções, daqueles que frequentam os seus cursos apenas para poderem progredir na carreira, posicionando-se como meros "consumidores" daqueles. Se em relação aos primeiros o balanço da formação contínua é muito positivo, em relação aos segundos sucede exactamente o contrário. A directora do CEP de Sevilha declara compreender a preocupação das autoridades educativas em obrigar todos os professores para actualizarem a sua formação pedagógico-didáctica, mas defende que tal obriga a um esforço de resultados infrutíferos. Uma questão polémica.

Estas foram as segundas Jornadas de Trabalho em que um numeroso grupo de docentes do ensino universitário e do ensino secundário ligados à licenciatura em Ensino da Geografia participam activamente. Nas primeiras, Trobada D'Intercanvi de Experiènces, Geografia, Història, Art i Coneixement del Medi, que decorreram em Valência, em 1994, debateram-se, sobretudo, novas metodologias de ensino ${ }^{3}$.

Do balanço destas Jornadas, para os participantes portugueses ficou o contacto com um modelo de formação inicial de professores globalmente mais pobre que o desenvolvido na licenciatura em Ensino da Geografia e na Faculdade de Letras da Universidade de Lisboa, mas com um bem sucedido esforço de integração da formação teórica e prática. A formação contínua, incontestavelmente mais desenvolvida em Espanha, constitui uma inesgotável fonte de inspiração e de experiências para a sua implementação entre nós, quando a legislação portuguesa prevê diferentes modalidades ainda por explorar.

3 Ver CAM (1994) - Trobada D’Intercanvi de Experiènces, Geografia, Història, Art i Coneixement del Medi. Editorial ECIR, Paterna. 
As alterações na formação de professores pretendidas pelos responsáveis, quer do ICE da Universidade de Sevilha, quer do CEP daquela cidade, vão num mesmo sentido: a recusa da formação massificada, em favor de uma aposta séria na daqueles que estão mobilizados para o exercício da profissão.

Apesar das dúvidas que esta orientação poderá suscitar, ela decorre de uma experiência e reflecte uma avaliação que nos devem merecer a melhor atenção, designadamente quando se discute também entre nós o futuro da formação dos professores de Geografia. 